\title{
Modeling of Lung Function Recovery in Neuralgic Amyotrophy With Diaphragm Impairment
}

\author{
Brenda L Rice MD, Rendell W Ashton MD, Xiao-Feng Wang PhD, Steven J Shook MD, \\ Eduardo Mireles-Cabodevila MD, and Loutfi S Aboussouan MD
}

\begin{abstract}
BACKGROUND: Neuralgic amyotrophy is an inflammatory peripheral nerve disorder in which phrenic nerve involvement can lead to diaphragm paralysis. The prevalence, magnitude, and time course of diaphragm recovery are uncertain. METHODS: This study modeled the course of recovery of lung function in 16 subjects with diaphragm impairment from neuralgic amyotrophy. The first and last available vital capacity, sitting-to-supine decline in vital capacity, and maximal inspiratory pressures were compared. RESULTS: An asymptotic regression model analysis in 11 subjects with at least partial recovery provided estimates of the vital capacity at onset $(47 \%$, 95\% CI 25-68\%), the final vital capacity $(81 \%, 95 \%$ CI $62-101 \%)$, and the half-time to recovery (22 months, 95\% CI 15-43 months). In those subjects, there was a significant improvement between the first and last measured FVC (median $44-66 \%, P=.004$ ) and maximal inspiratory pressure (mean $34-51 \%, P=.004)$. Five subjects $(31 \%)$ with complete recovery had a final sitting-to-supine drop of vital capacity of $16 \%$ and a maximal predicted inspiratory pressure of $63 \%$. CONCLUSIONS: Sixty-nine percent of subjects with diaphragm impairment from neuralgic amyotrophy experience recovery of lung function and diaphragm strength, but recovery is slow and may be incomplete. Key words: brachial plexus neuritis; diaphragmatic paralysis; respiratory function tests; phrenic nerve; longitudinal study. [Respir Care 2017;62(10):1269-1276. (c) 2017 Daedalus Enterprises]
\end{abstract}

\section{Introduction}

Neuralgic amyotrophy is an inflammatory brachial plexus neuropathy manifesting as severe neck or shoulder

Drs Rice, Ashton, Mireles-Cabodevila, and Aboussouan are affiliated with the Respiratory Institute, Department of Pulmonary, Allergy, and Critical Care Medicine; Dr Wang is affiliated with the Department of Quantitative Health Sciences; and Dr Shook is affiliated with the Neurological Institute, Neuromuscular Center, Cleveland Clinic, Cleveland, Ohio.

Dr Rice presented a version of this work at the American Thoracic Society meeting, held May 14-19, 2010, in New Orleans, Louisiana, and published in abstract form.

Dr Aboussouan has disclosed a relationship with UpToDate/Wolters Kluwers. The other authors have disclosed no conflicts of interest.

Correspondence: Loutfi S Aboussouan MD, Cleveland Clinic, Respiratory Institute, 9500 Euclid Avenue, Desk A 90, Cleveland, OH 44195. E-mail: aboussl@ccf.org.

DOI: $10.4187 /$ respcare. 05568 pain and upper extremity weakness. ${ }^{1-3}$ It usually follows a triggering event, such as upper-respiratory tract infection, surgery, trauma, heavy backpack use, or vaccination. ${ }^{4-6}$ The diagnosis is based on the clinical signs and symptoms. An electromyogram demonstrating changes consistent with axonal degeneration affecting the muscles of the proximal arm, thumb flexion, or diaphragm, can support the diagnosis.

Neuralgic amyotrophy can involve one or both phrenic nerves with resultant diaphragm paresis or paralysis. Chest radiographs, obtained in the evaluation of the neuralgic amyotrophy pain, uncover incidental diaphragm elevation in about $7-25 \%$, with bilateral elevation in up to $27 \%$ of those. ${ }^{4,5,7}$ Unilateral paralysis of the diaphragm is asymptomatic in the majority of subjects. ${ }^{8-10}$

The prevalence, magnitude, and course of recovery of diaphragm dysfunction due to neuralgic amyotrophy have been the subject of some controversy in the few case series on this topic. ${ }^{2,5,11,12}$ For instance, recovery has been reported to be unlikely in one study, with no recovery expected in bilateral diaphragm paralysis and long-term complete improvement in only 1 of 4 subjects with unilateral 
diaphragm paralysis. ${ }^{12}$ Another study indicated evidence of at least some recovery in $70 \%$ of subjects with bilateral diaphragm paralysis with continued improvement in most beyond 3 y. ${ }^{11}$ In contrast, another study showed that $50 \%$ of subjects with either bilateral or unilateral diaphragm paralysis had improvements in pulmonary function but that none had an improvement beyond $3 \mathrm{y} .{ }^{2}$ The goal of this study was to evaluate the prevalence of recovery of vital capacity in subjects with neuralgic amyotrophy associated with unilateral or bilateral diaphragm impairment, assess whether this recovery correlates with improvements in measures of respiratory muscle and diaphragmatic strength, and mathematically model the extent and time course of recovery.

\section{Methods}

\section{Study Subjects}

The study was approved by our institutional review board. Subjects included those with a diagnosis of neuralgic amyotrophy evaluated and followed between January 2002 and December 2012 in the Neuromuscular Disease Program of the Respiratory Institute at our institution. The diagnosis of neuralgic amyotrophy was confirmed by a neuromuscular neurologist, based on a combination of clinical history (including severe, acute onset pain in the neck, shoulder, or arms, followed by paresis and atrophy), neurological examination, and/or confirmatory electrodiagnostic findings. ${ }^{7}$ Additional inclusion criteria included: unilateral or bilateral diaphragm impairment confirmed by imaging studies, baseline pulmonary function tests after the onset of the diaphragm impairment, and at least one subsequent pulmonary function test.

\section{Pulmonary Function Measurements}

Spirometry was performed using the MasterLab Pro system (Erich Jaeger, Friedberg, Germany). All pulmonary function testing was performed in accordance with the American Thoracic Society specifications ${ }^{13}$ and the third National Health and Nutrition Examination Survey (NHANES III) reference values. ${ }^{14}$ Obstructive lung disease was considered present when the $\mathrm{FEV}_{1} / \mathrm{FVC}$ was below the lower limit of normal from those references. For testing of respiratory muscle strength and, more specifically, diaphragm strength, maximal inspiratory muscle strength and the sitting-to-supine drop in vital capacity were obtained. ${ }^{15}$ Maximal inspiratory pressure was obtained from residual volume according to the American Thoracic Society/European Respiratory Society statement on respiratory muscle testing. ${ }^{16}$ Predicted values for maximal inspiratory pressure were according to the sex- and age-specific equations of Black and Hyatt. ${ }^{17}$ The defini-

\section{QUICK LOOK}

\section{Current knowledge}

Neuralgic amyotrophy is an inflammatory brachial plexus neuropathy, which can be associated with diaphragm paresis or paralysis due to phrenic nerve involvement in $7-25 \%$ of patients. The prevalence, magnitude, and time course of recovery of diaphragm dysfunction due to neuralgic amyotrophy are uncertain. Whereas one study shows at least some recovery of diaphragm function in $70 \%$ with continued improvement beyond $3 \mathrm{y}$, other studies show much lower recovery rates with no improvement expected beyond $3 \mathrm{y}$.

\section{What this paper contributes to our knowledge}

In the present study, $69 \%$ of subjects with diaphragm impairment in the context of neuralgic amyotrophy experienced at least partial recovery of lung function. However, only $31 \%$ recovered to a normal final vital capacity, and even those with apparent full recovery had residual diaphragm impairment on more detailed testing. The time course of recovery was prolonged, with a time to the midpoint of recovery of nearly $2 \mathrm{y}$.

tion of recovery of vital capacity was modeled after that for bronchodilator responsiveness as a $\geq 200-\mathrm{mL}$ absolute improvement and $\mathrm{a} \geq 12 \%$ increase between the nadir FVC and the last measured FVC. ${ }^{18}$ Of subjects with at least some recovery of vital capacity, those with a last measured vital capacity of $>80 \%$ predicted were considered to have full recovery, and the rest were considered to have partial recovery.

\section{Analyses}

Continuous variables were presented as mean \pm SD or median (interquartile range), and comparisons of variables between groups with or without recovery were performed by an independent $t$ test or the Mann-Whitney U test, depending on whether the data were normally or nonnormally distributed, respectively. Comparison of first and last available pulmonary function variables were performed by a 2-tailed paired $t$ test or the Wilcoxon signed-rank test for normally or non-normally distributed data, respectively. Two-by-two cross-tabulation analyses were performed using the chi-square test or, alternatively, the Fisher exact test when any cell of the contingency table contained $<5$ subjects.

Review of the course of recovery in subjects who improved showed an initial rapid improvement in the vital 


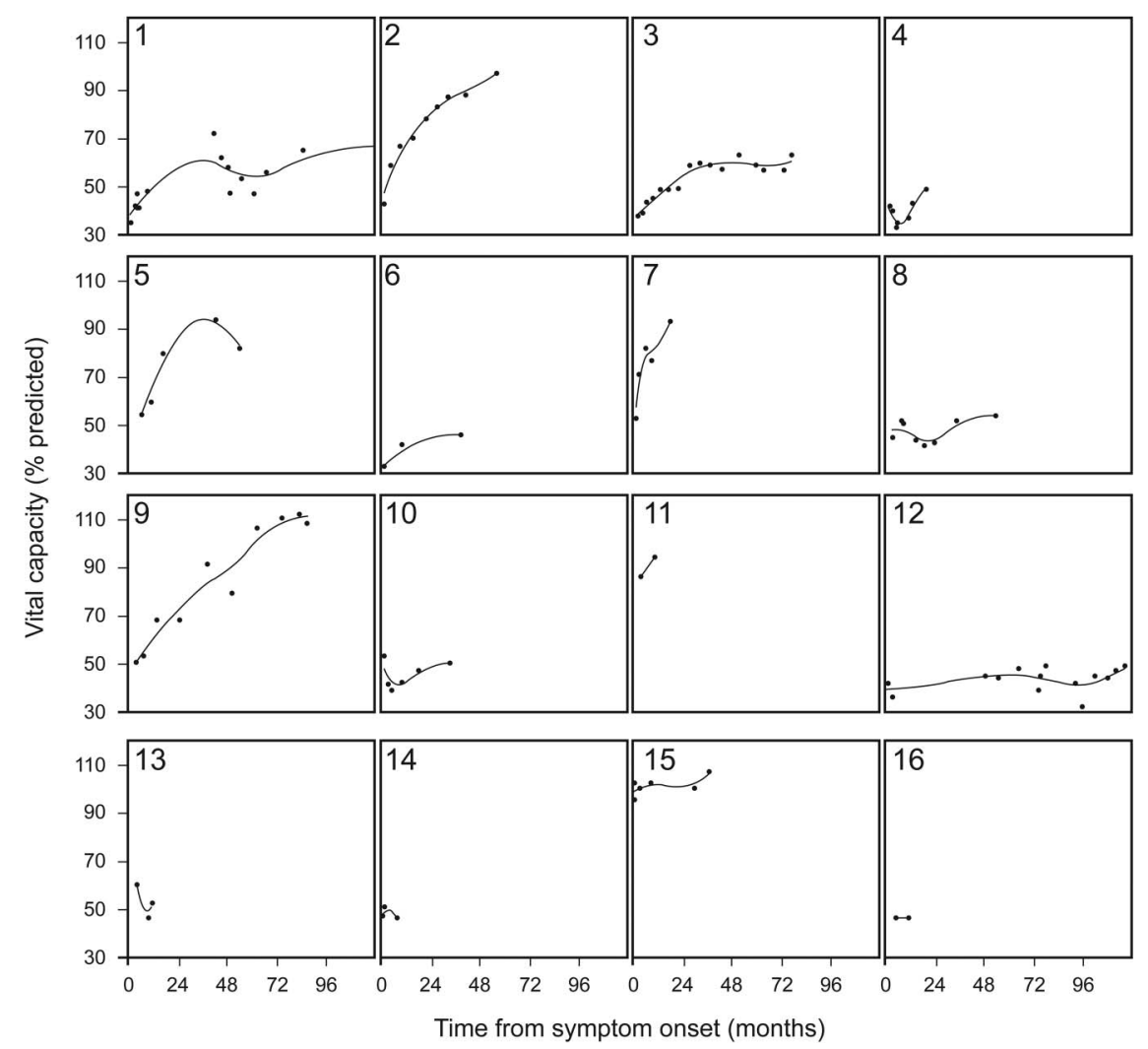

Fig. 1. Course of lung function in 16 subjects with neuralgic amyotrophy and diaphragm impairment. Shown are individual plots of sequential FVC measurements expressed as percent of predicted values, plotted over time from onset of shortness of breath expressed in months, with a smoothing curve. Subjects 1-11 are those with at least partial recovery of lung function over time, and subjects 12-16 are those with no recovery of lung function.

capacity, followed by progressive slowing and plateau (Fig. 1). Therefore, an asymptotic regression function was used to model the mean course of recovery, using a non-linear mixed-effects model to fit the data. ${ }^{19}$ Such a model is ideal to evaluate repeated measures on the same subjects, imbalances in the number of observations between subjects, and data obtained at variable intervals. ${ }^{19}$ The mean function representing the percent of predicted vital capacity as a function of time $t$ was given by the equation, $\mu(\mathrm{t})=\beta_{1}+\left(\beta_{2}-\beta_{1}\right) \times \mathrm{e}^{-\beta 3 \times \mathrm{t}}$, where the parameter $\beta_{1}$ represents the vital capacity at full recovery, $\beta_{2}$ represents the vital capacity at the onset of symptoms, and $\beta_{3}$ is a time scale parameter such that $\ln (2) / \beta_{3}$ represents the half-time to recovery. In this model, the response variable approaches a horizontal asymptote as t increases (Fig. 2).

Random effects were also considered in the regression analysis. A number of candidate models were compared, including models with reduced model parameters and models with and without random effects. The final model was determined by the Akaike information criterion, a measure of the relative quality of statistical models for the given set of data.

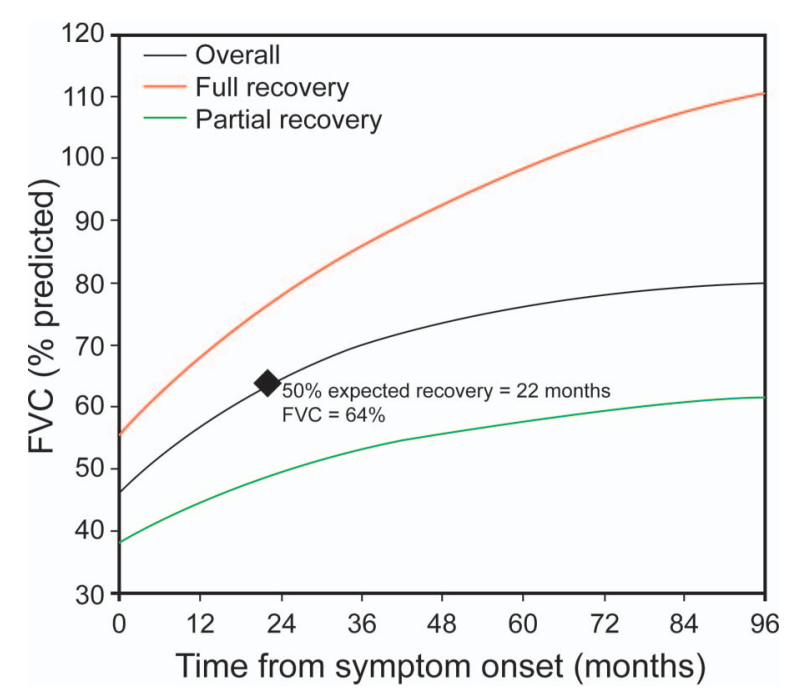

Fig. 2. Lung function recovery in subjects with at least partial recovery of lung function. The plot is based on the 3-parameter asymptotic regression model shown in Table 2 and shows the composite plot as well as plots stratified by extent of recovery. The point in time at which half of the expected recovery has occurred is shown at 22 months ( $95 \% \mathrm{Cl} 15-43$ months). 


\section{Lung Function Recovery in Neuralgic Amyotrophy}

Table 1. Comparison of Demographic, Clinical, and Initial Pulmonary Function Characteristics in Subjects With or Without Recovery From Diaphragm Impairment in Neuralgic Amyotrophy

\begin{tabular}{|c|c|c|c|c|}
\hline Characteristics & All Subjects $(N=16)^{*}$ & No Recovery $(n=5)^{*}$ & Recovery $(n=11)^{*}$ & $P \dagger$ \\
\hline Age, mean $\pm \mathrm{SD}$ y & $55 \pm 16$ & $46 \pm 14$ & $59 \pm 15$ & $.12 \div$ \\
\hline Days until first spirometry, mean \pm SD d & $77 \pm 63$ & $79 \pm 70$ & $76 \pm 63$ & $.94 \div$ \\
\hline Body mass index, mean $\pm \mathrm{SD} \mathrm{kg} / \mathrm{m}^{2}$ & $32 \pm 5$ & $35 \pm 6$ & $30 \pm 4$ & $.07 \ddagger$ \\
\hline FVC, median (IQR) \% predicted & $47(42-54)$ & $47(44-78)$ & $44(38-53)$ & $.32 \S$ \\
\hline Maximal inspiratory pressure, mean \pm SD $\%$ predicted & $38 \pm 16(n=11)$ & $56 \pm 15(n=2)$ & $35 \pm 15(n=9)$ & $.11 \ddagger$ \\
\hline Maximal expiratory pressure, mean $\pm \mathrm{SD} \%$ predicted & $57 \pm 21(n=11)$ & $61 \pm 0.7(n=2)$ & $56 \pm 23(n=9)$ & $.82 \ddagger$ \\
\hline Supine decline in vital capacity, mean \pm SD $\%$ & $40 \pm 16(n=14)$ & $29 \pm 11(n=5)$ & $46 \pm 16(n=9)$ & .057 \$ \\
\hline Diabetes, $\%$ & 25 & 20 & 27 & $>.99 \|$ \\
\hline Ever smoker, \% & 44 & 40 & 45 & $>.99 \|$ \\
\hline Obstructive lung impairment, $\%$ & 38 & 20 & 45 & $.59 \|$ \\
\hline Bilateral impairment, \% & 50 & 20 & 64 & $.28 \|$ \\
\hline Spirometries per subject, mean $\pm \mathrm{SD}$ & $7.3 \pm 4.9$ & $5.6 \pm 4.9$ & $8.1 \pm 4.9$ & $.36 \ddagger$ \\
\hline Months from onset to last spirometry, mean \pm SD months & $48 \pm 39$ & $37 \pm 45$ & $53 \pm 37$ & $.47 \ddagger$ \\
\hline $\begin{array}{l}\text { * Number of subjects in the analysis unless otherwise specified. } \\
\dagger P \text { value for differences between the no recovery and recovery groups. } \\
\ddagger \text { Independent-samples } t \text { test. } \\
\S \text { Mann-Whitney U test. } \\
\| \text { Fisher exact test. } \\
\text { IQR = interquartile range }\end{array}$ & & & & \\
\hline
\end{tabular}

A linear mixed-effects model analysis, with random subject effects, was used to assess the correlation of the vital capacity to the inspiratory muscle strength, both expressed as a percent of predicted value, and the sitting-to-supine drop in lung function (expressed as the percentage change from the sitting position). Model checking and diagnostics confirmed the validity of the model's assumptions. Statistical significance was set at $<0.05$. All analyses were performed with SAS 9.3 (SAS Institute, Cary, North Carolina).

\section{Results}

\section{Participants' Characteristics}

We identified 16 subjects ( 15 males, 1 female) with a diagnosis of neuralgic amyotrophy and diaphragmatic paralysis. Mean age was $55 \pm 16$ y (range $27-88$ y). Four subjects $(25 \%)$ had diabetes, and $6(38 \%)$ had obstructive lung disease. The diaphragm impairment was bilateral in 8 (50\%), of which 2 had a preexisting impairment on the contralateral side at the time of onset, and 6 had bilateral onset of diaphragm dysfunction. In 14 subjects, there were symptoms of neck/shoulder pain or arm weakness preceding the onset of pulmonary symptoms by a median of $4 \mathrm{~d}$ (interquartile range 2-14 d). Electromyogram studies of the upper limbs and/or diaphragm were performed in 14 subjects and were diagnostic of neuralgic amyotrophy affecting the brachial plexus or phrenic nerve in 7. The FVC obtained after the onset of shortness of breath symptoms was severely reduced, and the mean body mass index was in the obese range (Table 1).

\section{Prevalence and Course of Recovery of Lung Function}

On follow-up, 11 of 16 subjects $(69 \%)$ had at least partial recovery of the vital capacity (Fig. 1, subjects 1-11), whereas 5 (31\%) had no recovery (Fig. 1, subjects 12-16). Of the 11 with at least partial recovery, 5 were considered to have full recovery (Fig. 1, subjects 2, 5, 7, 9, and 11), all of whom had a highest measured vital capacity of $>90 \%$, and 6 had partial recovery (Fig. 1, subjects 1, 3, 4, 6, 8, and 10). Those who had no recovery tended to be younger relative to those who experienced at least partial recovery and to have a larger body mass index, a greater maximal inspiratory pressure, and a lesser percentage decline in the vital capacity from sitting to supine position, but those differences did not reach statistical significance (Table 1). There was no difference in the vital capacity, maximal expiratory pressure, time to the first spirometry, prevalence of diabetes, obstructive lung disease, or presence of bilateral impairment between groups with versus without recovery (Table 1).

For the 11 subjects who had at least partial recovery, non-linear mixed-effects modeling showed that a 3-parameter asymptotic regression provided an adequate fit of the available vital capacity recovery data for the overall group as well as for the full and partial recovery groups (Table 2 and Fig. 2). For the overall group, those parameters in- 


\section{Lung Function Recovery in Neuralgic Amyotrophy}

Table 2. Asymptotic Regression Fit in Neuralgic Amyotrophy Subjects With at Least Partial Diaphragm Function Recovery

\begin{tabular}{|c|c|c|c|c|c|c|c|}
\hline \multirow{2}{*}{ Parameter } & \multicolumn{2}{|c|}{ Both Groups } & \multicolumn{2}{|c|}{ Full Recovery } & \multicolumn{2}{|l|}{ Partial Recovery } & \multirow{2}{*}{$P^{*}$} \\
\hline & Estimate $(95 \% \mathrm{CI})$ & $P$ & Estimate $(95 \% \mathrm{CI})$ & $P$ & Estimate (95\% CI) & $P$ & \\
\hline $\begin{array}{l}\text { Projected final vital capacity } \\
\qquad\left(\beta_{1}\right), \% \text { predicted }\end{array}$ & $81(62-101)$ & $<.001$ & $128(109-147)$ & $<.001$ & $64(49-80)$ & $<.001$ & $<.001$ \\
\hline FVC at onset $\left(\beta_{2}\right), \%$ predicted & $47(25-68)$ & $<.001$ & $56(52-60)$ & $<.001$ & $38(35-42)$ & $<.001$ & $<.001$ \\
\hline $\ln 2 / \beta_{3}$ (months) $\dagger$ & $22(15-43)$ & .003 & $46(32-84)$ & $<.001$ & 30 (14 to indeterminate) & .11 & .58 \\
\hline
\end{tabular}

Table 3. Comparison of First With Last Available Vital Capacity, Sitting-to-Supine Decline in Vital Capacity, and Maximal Inspiratory and Expiratory Strength, Stratified by Recovery Status

\begin{tabular}{|c|c|c|c|c|c|c|c|c|}
\hline \multirow{2}{*}{ Parameters } & \multicolumn{4}{|c|}{ Recovery } & \multicolumn{4}{|c|}{ No Recovery } \\
\hline & $n^{*}$ & First & Last & $P$ & $n^{*}$ & First & Last & $P$ \\
\hline FVC, median (IQR) \% predicted & 11 & $44(38-53)$ & $66(50-94)$ & $.004 \dagger$ & 5 & $47(44-78)$ & $49(46-80)$ & $.72 \dagger$ \\
\hline Sitting-to-supine vital capacity drop, mean \pm SD $\%$ & 9 & $46 \pm 16$ & $31 \pm 21$ & $.07 \ddagger$ & 4 & $28 \pm 12$ & $32 \pm 26$ & $.62 \ddagger$ \\
\hline Maximal inspiratory pressure, mean $\pm \mathrm{SD} \%$ predicted & 9 & $34 \pm 15$ & $51 \pm 23$ & $.004 \div$ & 2 & $56 \pm 15$ & $69 \pm 18$ & $.12+$ \\
\hline Maximal expiratory pressure, mean \pm SD $\%$ predicted & 9 & $56 \pm 23$ & $57 \pm 23$ & $.82 \div$ & 2 & $61 \pm 0.7$ & $79 \pm 18$ & $.40+$ \\
\hline $\begin{array}{l}* n=\text { number of available pairs for each comparison. } \\
\dagger \text { Wilcoxon signed-rank test. } \\
\ddagger \text { Paired } t \text { test. } \\
\text { IQR }=\text { interquartile range }\end{array}$ & & & & & & & & \\
\hline
\end{tabular}

cluded: a final vital capacity projected in the model to be $81 \%$ predicted, a vital capacity at onset of symptoms projected in the model to be $47 \%$ predicted, and a time scale factor such that the time for half of the expected recovery to occur was 22 months (95\% CI 15-43 months). At that half-time, the vital capacity was still moderately reduced at $64 \%$. Differences between the full and partial recovery group included a significantly lower percent of predicted vital capacity at onset of symptoms in the partial recovery group relative to the full recovery group (38\% vs $56 \%$, $P<.001)$ and a lower projected final vital capacity $(64 \%$ vs $128 \%, P<.001)$ but no difference in the half-time to recovery (Table 2 and Fig. 2). In the subjects with full recovery of vital capacity, the final percentage sitting-tosupine drop of vital capacity averaged $16 \pm 5 \%$, and the final maximal inspiratory pressure averaged $63 \pm 28 \%$.

\section{Respiratory and Diaphragmatic Variables}

The average number of spirometry measurements per subject was $7.3 \pm 4.9$, and the mean time from onset of shortness of breath symptoms to the last spirometry was $48 \pm 39$ months (range 9-137 months), without a significant difference between those with versus those without recovery of lung function (Table 1). There was a signifi- cant improvement from first to last available FVC and maximal inspiratory pressure for subjects assessed to have at least partial recovery in lung function, but not in those without recovery (Table 3 ). In contrast, there was no significant change in maximal expiratory pressure in either group. A similar trend for an improvement in the sittingto-supine decline in vital capacity was noted in those with at least partial recovery (Table 3). In linear mixed-effects model analysis with random subject effects (including all 16 subjects), the measured percent of predicted FVC was positively correlated with the percent of predicted inspiratory muscle pressure and negatively correlated with the percentage change in lung function from sitting to supine position (Table 4).

\section{Discussion}

\section{Synopsis of Study Findings}

In the present study, $69 \%$ of subjects with diaphragm impairment in the context of neuralgic amyotrophy experience at least partial recovery of lung function. However, this is tempered by the findings that only $31 \%$ recover to a normal final vital capacity, that even those with apparent full recovery have residual diaphragm impairment on more 


\section{Lung Function Recovery in Neuralgic Amyotrophy}

Table 4. Linear Mixed Regression Model With Random Subject Effects Between FVC and Measures of Respiratory and Diaphragmatic Strength in All Subjects

\begin{tabular}{clccc}
\hline \hline Variable & Effect & Estimate & $\begin{array}{c}\text { Standard } \\
\text { Error }\end{array}$ & $P$ \\
\hline Maximal inspiratory & Intercept & 36.3 & 6.7 & $<.001$ \\
pressure, \% predicted & Slope & 0.48 & 0.09 & $<.001$ \\
Change in sitting-to-supine & Intercept & 72.9 & 5.7 & $<.001$ \\
vital capacity, \% & Slope & -0.28 & 0.09 & .002 \\
\hline
\end{tabular}

detailed testing, and that the course of recovery is prolonged, with a time to the mid-point of recovery of nearly $2 \mathrm{y}$. Of note, neither the presence of diabetes nor bilateral diaphragm impairment is an impediment to the recovery. For those with at least partial recovery, there were corresponding improvements in vital capacity and in measures of respiratory and diaphragm strength. Further, the percent of predicted vital capacity correlated with measures of respiratory and diaphragm strength.

\section{Predictors of Recovery}

In this study, $56 \%$ of the subjects were obese and $25 \%$ had diabetes, proportions that are greater than expected in the general population. Whether obesity and diabetes are risk factors for the development of diaphragm impairment from neuralgic amyotrophy is uncertain. However, the presence of diabetes did not adversely impact recovery. Alternatively, a possible trend toward a greater body mass index in individuals who did not recover over time was noted. There was a significantly higher vital capacity at onset of the diaphragm impairment in those with full recovery compared with those with partial recovery.

Previous studies have reported less recovery in diaphragm strength in bilateral versus unilateral diaphragm paralysis. ${ }^{5,11,12}$ A distinction may need to be made between new impairment in the setting of preexisting contralateral diaphragm elevation and bilateral onset of diaphragm impairment. For instance, 5 of our 6 subjects with bilateral onset of diaphragm impairment had at least partial recovery of lung function (subjects 2, 5, and 7 with complete recovery, subjects 3 and 4 with partial recovery, and subject 12 with no recovery). In contrast, the two subjects (subjects 6 and 8) with preexisting contralateral impairment recovered only partially, probably reflecting the longer-standing and possibly permanent impairment of the contralateral diaphragm.

\section{Rate of Recovery}

An asymptotic regression model provides an estimate of the time course of diaphragm function, with no significant difference in the rate of recovery between full and partial responders, such that the overall recovery half-time is nearly 2 y (22 months). Although the $95 \%$ CI for this estimate is large, the lower end of that range is still $>1 \mathrm{y}$ (14 months), and full recovery may not be achieved for $>3 \mathrm{y}$. The rate of recovery of respiratory muscle strength has not been previously reported, but the slow and prolonged course was noted. ${ }^{5,11}$ This course parallels that of the brachial plexus injury in neuralgic amyotrophy. For instance, a Mayo Clinic series of 99 individuals with brachial plexus neuropathy reported recovery rates based on the actuarial method of life-person analysis of 36\% within the first year, $75 \%$ by the end of the second year, and $89 \%$ by the end of the third year. ${ }^{5}$ These rates did not take into account the severity or type of plexus lesion, and only 7 had diaphragmatic paralysis.

Our results cannot be extrapolated to subjects with other causes of phrenic nerve injury. For example, a plateau of recovery appears to occur at approximately $1-2$ y in phrenic nerve injury following coronary artery revascularization, which is sooner than what we saw in our data. ${ }^{20}$ Similarly, in a long-term longitudinal study of recovery of lung function in subjects with diaphragm impairment from diverse causes (but none having neuralgic amyotrophy), 43\% improved the vital capacity by $400 \mathrm{~mL}$ by the first year, compared with only $27 \%$ in our study when our data were analyzed along that same criterion. ${ }^{21}$

\section{Residual Impairment}

Long-term impairment of pulmonary function in neuralgic amyotrophy affecting the phrenic nerve is common, with 5 of $16(31 \%)$ individuals experiencing no recovery and 6 of $16(37 \%)$ experiencing only partial recovery. Further, of the 6 subjects (31\%) who experienced apparent full recovery, residual impairment is suggested by more detailed testing. Specifically, although the normal 95\% upper confidence limit for the sitting-to-supine drop in lung capacity may be as high as $19 \%,{ }^{22}$ our mean final reading of $16 \%$ in the 5 subjects with full recovery is more than twice the expected mean of 5-8\%, ${ }^{22-24}$ which, along with a persistently reduced maximal inspiratory pressure (63\%), suggests that residual diaphragm impairment may persist even after apparent complete lung recovery, a finding that is consistent with other studies. For instance, 3 of 4 cases with diaphragm elevation reported by Tsairis et $\mathrm{al}^{5}$ had elevated or immobile diaphragms on fluoroscopy 2.5 $4 \mathrm{y}$ after the onset of the disease, although they had functional recovery from their disease. In another study, phrenic nerve conduction and diaphragm function remained abnormal for up to $4 \mathrm{y} .{ }^{25}$ This pattern replicates the prognosis of the neuralgic amyotrophy pain, with $51.7 \%$ having no recovery from the sensory symptoms and only $28.7 \%$ experiencing full recovery. ${ }^{4}$ 


\section{Lung Function Recovery in Neuralgic Amyotrophy}

\section{Possible Mechanisms and Pathophysiology of Delayed and Partial Recovery}

The poor or delayed recovery of diaphragm impairment in neuralgic amyotrophy may be due to a combination of factors, including the length of the phrenic nerve and its proximal cervical root origin (C3 to $\mathrm{C} 5)^{25,26}$ a pathology of demyelination and axonal neuropathy, 8,27 the possible widespread localization of the injury, ${ }^{28}$ nerve torsion at sites of hourglass constriction (documented in affected nerves of the arm), ${ }^{27,29,30}$ or persistent immunologic triggers, such as anti-ganglioside antibodies ${ }^{4}$ or CD8-positive T lymphocytes. ${ }^{27}$ Alternatively, the improvement in vital capacity over time may be due to progressive conditioning of inspiratory muscles other than the diaphragm. This possibility is certainly in line with the finding of residual diaphragm impairment despite normalization of the vital capacity in individuals with full recovery. It is also consistent with the finding that the improvement in sitting-tosupine drop in vital capacity (a more specific marker of diaphragm strength $)^{15}$ is not as significant as the improvement in maximal inspiratory pressure (a marker of general inspiratory muscle strength) (Table 3 ).

\section{Limitations}

Our series is small but captures a large amount of spirometric and respiratory muscle strength data, with a mean follow-up of $4 \mathrm{y}$ (Table 1). The period of follow-up was short in some individuals, and an improvement over a longer period of follow-up could potentially have been missed in the group evaluated not to have recovery. Also, the interval from first to last spirometry was not consistent between individuals. However, there were no significant imbalances in the duration of follow-up or number of spirometries between individuals with or without recovery of lung function (Table 1).

The study assessed all individuals with diaphragm impairment in the context of neuralgic amyotrophy and therefore included unilateral and bilateral diaphragm impairment. Further, our findings are biased to symptomatic individuals who present to medical attention because of shortness of breath symptoms developing in the context of diaphragm impairment following neuralgic amyotrophy. This may be explained by the fact that the respiratory muscles have a large reserve and that symptoms typically do not develop until substantial muscle strength is lost, perhaps accounting for the relatively large percentage of bilateral diaphragm involvement in our data. Bilateral diaphragm involvement can reflect either bilateral onset of neuralgic amyotrophy or a preceding older contralateral episode with no diaphragm recovery. ${ }^{9}$ The latter scenario would not be unexpected because neuralgic amyotrophy can be recurrent in $25 \%$ of individuals. ${ }^{7}$
Epidemiologic data have reported a male/female ratio of $2: 1$ in neuralgic amyotrophy, ${ }^{4,5,31}$ yet 15 of our 16 subjects with diaphragm impairment were males. There are several case reports of neuralgic amyotrophy with diaphragmatic paralysis in women ${ }^{10,25,32}$; however the largest studies addressing diaphragm impairment in that context have been almost exclusively in males with a mean age in the middle-age range as in our study.2,11,12 Although this may suggest that males are at significantly higher risk of developing neuralgic amyotrophy with phrenic nerve involvement compared with neuralgic amyotrophy with isolated brachial plexus lesions, this sex imbalance is unexpected, given the suspected autoimmune etiology of the disease. The high prevalence of males may reflect a bias in reporting or one due to level of activity. ${ }^{4}$

\section{Conclusions}

This study provides an objectively quantifiable assessment of the extent of impairment and time frame of recovery of pulmonary function in diaphragm impairment from neuralgic amyotrophy. Important clinical implications are to maintain a high clinical index of suspicion for bilateral diaphragm involvement in that context, provide optimistic but tempered counseling on the potential and course of recovery, assess recovery by regular pulmonary function testing (perhaps twice per year), and offer supportive interim approaches such as weight loss or nocturnal noninvasive ventilator support when the diaphragm dysfunction is causing sleep-disordered breathing. ${ }^{33}$ Surgical alternatives, such as neurolysis, neurorrhaphy, and nerve grafting, have been used in neuralgic amyotrophy of the upper extremity, ${ }^{27}$ but a surgical treatment algorithm excludes patients with neuralgic amyotrophy from phrenic nerve surgery. ${ }^{34}$ For those with diaphragm impairment who do not experience recovery after $2-3 \mathrm{y}$, diaphragm plication is an option. ${ }^{34-37}$

\section{REFERENCES}

1. Sathasivam S, Lecky B, Manohar R, Selvan A. Neuralgic amyotrophy. J Bone Joint Surg Br 2008;90(5):550-553.

2. Tsao BE, Ostrovskiy DA, Wilbourn AJ, Shields RW Jr. Phrenic neuropathy due to neuralgic amyotrophy. Neurology 2006;66(10): 1582-1584.

3. van Alfen N, van Engelen BG, Reinders JW, Kremer H, Gabreëls FJ. The natural history of hereditary neuralgic amyotrophy in the Dutch population: two distinct types? Brain 2000;123(Pt 4):718-723.

4. van Alfen N, van Engelen BG. The clinical spectrum of neuralgic amyotrophy in 246 cases. Brain 2006;129(Pt 2):438-450.

5. Tsairis P, Dyck PJ, Mulder DW. Natural history of brachial plexus neuropathy. Report on 99 patients. Arch Neurol 1972;27(2):109-117.

6. Nylund T, Mattila VM, Salmi T, Pihlajamäki HK, Mäkelä JP. Recovery of brachial plexus lesions resulting from heavy backpack use: a follow-up case series. BMC Musculoskelet Disord 2011;12:62.

7. van Alfen N. The neuralgic amyotrophy consultation. J Neurol 2007; 254(6):695-704. 


\section{Lung Function Recovery in Neuralgic Amyotrophy}

8. Cruz-Martínez A, Barrio M, Arpa J. Neuralgic amyotrophy: variable expression in 40 patients. J Peripher Nerv Syst 2002;7(3):198-204.

9. Kumar A, Mireles-Cabodevila E, Mehta AC, Aboussouan LS. Sudden onset of dyspnea preceded by shoulder and arm pain. Ann Am Thorac Soc 2016;13(12):2261-2265.

10. Kumar N, Folger WN, Bolton CF. Dyspnea as the predominant manifestation of bilateral phrenic neuropathy. Mayo Clin Proc 2004; 79(12):1563-1565.

11. Hughes PD, Polkey MI, Moxham J, Green M. Long-term recovery of diaphragm strength in neuralgic amyotrophy. Eur Respir J 1999; 13(2):379-384.

12. Mulvey DA, Aquilina RJ, Elliott MW, Moxham J, Green M. Diaphragmatic dysfunction in neuralgic amyotrophy: an electrophysiologic evaluation of 16 patients presenting with dyspnea. Am Rev Respir Dis 1993;147(1):66-71.

13. American Thoracic Society. Standardization of spirometry, 1994 update. Am J Respir Crit Care Med 1995;152(3):1107-1136.

14. Hankinson JL, Odencrantz JR, Fedan KB. Spirometric reference values from a sample of the general U.S. population. Am J Respir Crit Care Med 1999;159(1):179-187.

15. Mier-Jedrzejowicz A, Brophy C, Moxham J, Green M. Assessment of diaphragm weakness. Am Rev Respir Dis 1988;137(4):877-883.

16. American Thoracic Society/European Respiratory Society. ATS/ERS Statement on respiratory muscle testing. Am J Respir Crit Care Med 2002;166(4):518-624.

17. Black LF, Hyatt RE. Maximal respiratory pressures: normal values and relationship to age and sex. Am Rev Respir Dis 1969;99(5):696702 .

18. American Thoracic Society. Lung function testing: selection of reference values and interpretative strategies. Am Rev Respir Dis 1991; 144(5):1202-1218.

19. Pinheiro JC, Bates DM. Mixed-effects models in S and S-PLUS. New York: Springer; 2000:511-521.

20. Wilcox PG, Paré PD, Pardy RL. Recovery after unilateral phrenic injury associated with coronary artery revascularization. Chest 1990; 98(3):661-666.

21. Gayan-Ramirez G, Gosselin N, Troosters T, Bruyninckx F, Gosselink R, Decramer M. Functional recovery of diaphragm paralysis: a long-term follow-up study. Respir Med 2008;102(5):690-698.

22. Allen SM, Hunt B, Green M. Fall in vital capacity with posture. Br J Dis Chest 1985;79(3):267-271.

23. Meysman M, Vincken W. Effect of body posture on spirometric values and upper airway obstruction indices derived from the flow- volume loop in young nonobese subjects. Chest 1998;114(4):10421047.

24. Vilke GM, Chan TC, Neuman T, Clausen JL. Spirometry in normal subjects in sitting, prone, and supine positions. Respir Care 2000; 45(4):407-410

25. Lahrmann H, Grisold W, Authier FJ, Zifko UA. Neuralgic amyotrophy with phrenic nerve involvement. Muscle Nerve 1999;22(4): 437-442.

26. Subramony SH. AAEE case report \#14: neuralgic amyotrophy (acute brachial neuropathy). Muscle Nerve 1988;11(1):39-44.

27. Pan Y, Wang S, Zheng D, Tian W, Tian G, Ho PC, et al. Hourglasslike constrictions of peripheral nerve in the upper extremity: a clinical review and pathological study. Neurosurgery 2014;75(1):10-22.

28. van Alfen N, Gabreels-Festen AA, Ter Laak HJ, Arts WF, Gabreëls FJ, van Engelen BG. Histology of hereditary neuralgic amyotrophy. J Neurol Neurosurg Psychiatry 2005;76(3):445-447.

29. Arányi Z, Csillik A, Dévay K, Rosero M, Barsi P, Böhm J, Schelle $\mathrm{T}$. Ultrasonographic identification of nerve pathology in neuralgic amyotrophy: enlargement, constriction, fascicular entwinement, and torsion. Muscle Nerve 2015;52(4):503-511.

30. Bradley WG, Madrid R, Thrush DC, Campbell MJ. Recurrent brachial plexus neuropathy. Brain 1975;98(3):381-398.

31. Martínez-Salio A, Porta-Etessam J, Berbel A, Alonso A, GutiérrezRivas E, Trueba J. Amyotrophic neuralgia: review of 37 cases. Rev Neurol 1998;27(159):823-826.

32. Kalluri M, Huggins JT, Strange C. A 56-year-old woman with arm pain, dyspnea, and an elevated diaphragm. Chest 2008;133(1):296299

33. Aboussouan LS. Sleep-disordered breathing in neuromuscular disease. Am J Respir Crit Care Med 2015;191(9):979-989.

34. Kaufman MR, Elkwood AI, Colicchio AR, CeCe J, Jarrahy R, Willekes LJ, et al. Functional restoration of diaphragmatic paralysis: an evaluation of phrenic nerve reconstruction. Ann Thorac Surg 2014;97(1):260-266

35. Odell JA, Kennelly K, Stauffer J. Phrenic nerve palsy and Parsonage-Turner syndrome. Ann Thorac Surg 2011;92(1):349-351.

36. Versteegh MI, Braun J, Voigt PG, Bosman DB, Stolk J, Rabe KF, Dion RA. Diaphragm plication in adult patients with diaphragm paralysis leads to long-term improvement of pulmonary function and level of dyspnea. Eur J Cardiothorac Surg 2007;32(3):449-456.

37. Stolk J, Versteegh MI. Long-term effect of bilateral plication of the diaphragm. Chest 2000;117(3):786-789. 